\title{
1 Street versus rooftop level concentrations of \\ 2 fine particles in a Cambridge street canyon
}

\author{
3 Prashant Kumar $^{1 *}$, Paul S. Fennell ${ }^{2,3}$, Allan N. Hayhurst ${ }^{2}$, Rex E. Britter ${ }^{1}$ \\ $4 \quad{ }^{1}$ Hopkinson Laboratory \\ 5 Department of Engineering \\ 6 University of Cambridge, CB2 1PZ, UK \\ $7 \quad{ }^{2}$ Department of Chemical Engineering \\ 8 University of Cambridge, CB2 3RA, UK \\ $9{ }^{3}$ Department of Chemical Engineering and Chemical Technology \\ 10 Imperial College London, SW7 2AZ, UK \\ $11 *$ Corresponding author \\ 12 Email: pp286@cam.ac.uk (Prashant Kumar); rb11@eng.cam.ac.uk (Rex Britter) \\ 13 Tel: + 44-(0) 1223332681 \\ 14 Fax: +44-(0)1223 765311, +44-(0)1223 332662 (Attention: Prashant Kumar) \\ 15 STATEMENT
}

16 The work described has not been submitted elsewhere for publication, in whole or

17 in part, and all the authors listed have approved the manuscript that is enclosed.

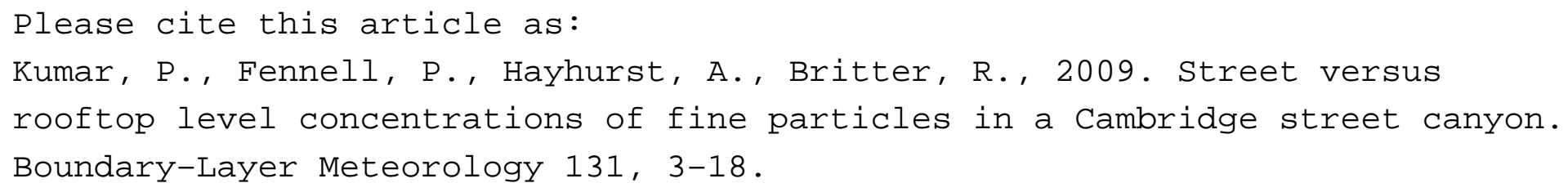




\section{Street versus rooftop level concentrations of 2 fine particles in a Cambridge street canyon}

\section{ABSTRACT}

4 Dispersion of particles, as evidenced by changes in their number distributions (PNDs) and 5 concentrations (PNCs), in urban street canyons, is still not well understood. This study compares 6 measurements by a fast-response particle spectrometer (DMS500) of the PNDs and the PNCs (5-

$71000 \mathrm{~nm}$, sampled at $1 \mathrm{~Hz}$ ) at street and rooftop levels in a Cambridge (UK) street canyon, and

8 examines mixing, physical and chemical conversion processes, and the competing influences of

9 traffic volume and rooftop wind speed on the PNDs and the PNCs in various size ranges. PNCs at

10 street level were $\approx 6.5$ times higher than at rooftop. Street-level PNCs followed the traffic volume

11 and decreased with increasing wind speed, showing a larger influence of wind speed on 30-300

$12 \mathrm{~nm}$ particles than on 5-30 nm particles. Conversely, rooftop PNCs in the 5-30 nm size range

13 increased with wind speed, whereas those for particles between 30-300 nm did not vary with wind 14 speed.

15 Keywords: Dispersion; Fine particles; Number concentration; Particle number 16 distribution; Street canyon 


\section{1. INTRODUCTION}

2 Current regulations address amount of the ambient particulate matter (PM) as

$3 \mathrm{PM}_{10}\left(D_{p} \leq 10 \mu \mathrm{m}\right)$ and $\mathrm{PM}_{2.5}\left(D_{p} \leq 2.5 \mu \mathrm{m}\right)$; these regulations use mass

4 concentrations of particles, not particle number concentrations (QUARG 1996).

5 Fine particles (below $1000 \mathrm{~nm}$, which is within $\mathrm{PM}_{1}$ ) are not included in the

6 regulatory limits because they contribute very little to the particle mass. Recent

7 toxicological studies have suggested that ultrafine particles, i.e., the fraction of

8 fine particles below $100 \mathrm{~nm}$ and the main component of ambient particles by

9 number, are more toxic than coarser particles, per unit mass (Oberdorster 2000).

10 Furthermore, epidemiological studies suggest a correlation between exposure to

11 ambient ultrafine particles at high number concentrations, and adverse health

12 effects (Peters and Wichmann 2001; Davidson et al. 2005). The case for using the

13 particle number concentration (PNC - the total number of particles, of all

14 sizes, per unit volume, whereas PND is the distribution function of the total

15 number of particles per unit volume against particle diameter) as a marker of

16 potential health hazards has been made by several researchers (Pope III 2000;

17 AQEG 2005), but progress has been hampered by a lack of standard methods and

18 instrumentation to measure the particle number concentrations. Furthermore, a

19 lack of a detailed understanding of the influence of ambient meteorology and

20 traffic flows on particle dispersion has been the major problem for the design of

21 effective mitigation strategies for particulate pollution in urban areas.

22 Vehicles are the main source of ultrafine particles in urban street canyons

23 (Schauer et al. 1996). Zones of high PNCs can be commonly seen in urban street

24 canyons, because of the limited dispersion of exhaust emissions due to the

25 surrounding built-up environment (Van Dingenen et al. 2004). Over the past two

26 decades several groups (Shi et al. 1999; Vardoulakis et al. 2002; Longley et al.

27 2003; Li et al. 2007) have studied the mass and number concentrations of particles

28 at different heights in urban street canyons, but the effects of mixing and physical

29 and chemical conversion of particles on particle numbers and size distributions

30 are still a matter of discussion.

31 Concentrations at street level can be much higher than those in

32 unobstructed locations with well-mixed air. The differences depend on traffic

33 characteristics, the geometry of the street canyon, advection of emissions from 
1 adjacent streets and turbulence produced by wind, atmospheric instability and 2 traffic, all making pollutant dispersion in urban streets a complex problem 3 (Bauman et al. 1982). There are several studies related to the spatial variation of 4 gaseous pollutants in urban street canyons. Thus Qin and Kot (1993) reported an 5 average vertical difference of approximately a factor of two for both $\mathrm{CO}$ and $\mathrm{NO}_{\mathrm{x}}$

6 between road level and the $25 \mathrm{~m}$ rooftop level. Zoumakis (1995) measured a drop

7 by a factor of 3 to 4 in $\mathrm{CO}$ concentrations at $29 \mathrm{~m}$ rooftop from road level.

8 According to Bauman et al. (1982) CO concentrations are higher by a factor of 4

9 at road level than at $60 \mathrm{~m}$ rooftop, while Vakeva et al. (1999) found a factor of 5

10 difference in the concentrations of $\mathrm{CO}, \mathrm{NO}_{\mathrm{x}}$ and $\mathrm{O}_{3}$ between street level $(3 \mathrm{~m})$ and 11 rooftop $(25 \mathrm{~m})$. All the above studies show a high correlation between levels of 12 primary (gaseous) pollutants and traffic volume, as well as strong concentration 13 gradients in a street canyon.

14 Conversely, there is very little (Bauman et al. 1982; Vakeva et al. 1999) 15 information on similar comparisons for fine particles. Vakeva et al. (1999) found 16 the number concentration of particles to be 5 times higher at street $(1.5 \mathrm{~m})$ level 17 than that at rooftop (25 m); also Bauman et al. (1982) reported a factor of 2 to 4 18 difference for fine particles between road level and $60 \mathrm{~m}$ rooftop. However, no 19 information on particle number distributions (PND) was presented in the above 20 two studies.

21 In this work PNDs were continuously measured in 5-1000 nm size range 22 at street and subsequently at rooftop level, in Cambridge (UK). This study is 23 novel in two respects; firstly, we used a recently developed instrument, the 'fast 24 response differential mobility spectrometer DMS500', to measure the PNDs, 25 providing near real-time continuous measurements, unlike other studies, which 26 used, for example, a scanning mobility particle sizer (SMPS), a electrical low27 pressure impactor (ELPI), an ultra particle condensation particle counter or optical 28 particle counters, either alone or in combination. Secondly, we measured a broad 29 range $(5-1000 \mathrm{~nm})$ of particles at a high sampling frequency $(10 \mathrm{~Hz})$. However, to 30 ensure maximal data quality, our experiments recorded the ten point rolling 31 average of the PNDs with a $1 \mathrm{~Hz}$ sampling frequency. The main aims of these 32 measurements were to determine the effects of mixing and physical and chemical 33 conversion processes, as well as the competing influences of rooftop wind speed 
1 and traffic volume on both the PNDs and particle number concentrations (PNCs)

2 in various size ranges, along with the production of new particles at both levels.

\section{2. EXPERIMENTAL}

\section{$4 \quad 2.1$ Description of Site}

5 Measurements were carried out on a small section of the street, Fen

6 Causeway, adjacent to the university's Department of Engineering in Cambridge

7 (UK). The section of street canyon studied is $200 \mathrm{~m}$ long, and runs approximately

8 east to west, as shown in Fig. 1. The road carries two-way traffic, and is $10 \mathrm{~m}$

9 wide, with one lane in each direction. The heights and frontages of the buildings

10 are not perfectly symmetrical, but they are continuous and broadly follow the

11 east-west line of the road. The roofs of the school buildings along the south side

12 are sloped and parallel to the road, whereas the geometries of those on the north

13 side are more complex. The buildings vary in height on both sides of the road: on

14 the south side from 18 to $22 \mathrm{~m}$ and on the north side from 15 to $22 \mathrm{~m}$. The average

15 height $(H)$ and the width $(W)$ (distance between buildings on opposite sides of the

16 road) of the street canyon at the measurement location are approximately $18 \mathrm{~m}$

17 and $20 \mathrm{~m}$, respectively, giving an aspect ratio $(H / W)$ near unity (Vardoulakis et al.

18 2003). Traffic is regulated by signals at both ends of the selected section through

19 pedestrian crossings. The street level sampling points were on the north side of the

20 road, $0.3 \mathrm{~m}$ away from the wall of Department of Engineering building, $3.05 \mathrm{~m}$

21 away from the kerb and approximately half-way along the length of the section;

22 altogether three different heights from 0.2 to $2.6 \mathrm{~m}$ were sampled. Rooftop

23 sampling was also performed on the north side of the road above the roof $(20 \mathrm{~m})$

24 of Department building and set back $3.35 \mathrm{~m}$ from the kerb. During the study winds

25 were from the southwest, with few sources of pollution upwind in the countryside.

26 Therefore, it was considered unlikely that there was a change in rooftop PNCs due to

27 a change in background PNCs on the two different days with similar weather.

\subsection{Instrumentation}

A fast response differential mobility spectrometer (DMS500) was used to

30 measure PNDs. A detailed description of the DMS500, its working principles,

31 applications in different areas and a comparison with other instruments (i.e., 
1 SMPS and ELPI) for road-side measurements can be seen elsewhere (Collings et

2 al. 2003; Biskos et al. 2005; Symonds et al. 2007). The DMS500 was calibrated

3 by using polystyrene spheres of known diameter (traceable) and also by

4 comparing the results from sampling an aerosol with those from a SMPS. The

5 calibration errors in the particle measurements and sample flow rate were about

$6 \quad 4.3 \%$ and $2 \%$, respectively.

$7 \quad$ Samples of air from both street and rooftop levels were obtained via a

8 thermally and electrically conductive sampling tube $(5.85 \mathrm{~mm}$ i.d.; length $5 \mathrm{~m})$

9 with a residence time of $\approx 0.3 \mathrm{~s}$. A cyclone, with a steel restrictor (with a hole of

10 diameter $1.0 \mathrm{~mm}$ ), was placed at the head of the sampling tube to maintain a flow

11 rate of $8 \times 10^{-3} \mathrm{~m}^{3} \mathrm{~min}^{-1}$ for the sample, and to reduce the pressure inside the

12 sampling tube to $0.25 \times 10^{5} \mathrm{~Pa}$ to improve the time response of the instrument and

13 to reduce agglomeration of particles (Biskos et al. 2005).

14 Theoretical estimates of particle losses in the sampling tube show that

15 diffusion and inertial impaction were the most important mechanisms for particles

16 below $15 \mathrm{~nm}$ (Hinds 1999), since the penetration (the fraction of the entering 17 particles leaving the tube) was $92-97 \%$ for particles between $5 \mathrm{~nm}$ and $10 \mathrm{~nm}$,

$1897-99 \%$ for particles between $10 \mathrm{~nm}$ and $15 \mathrm{~nm}$ and $99-99.99 \%$ for particles

19 between $15 \mathrm{~nm}$ and $1000 \mathrm{~nm}$. These penetrations indicate losses sufficiently small

20 to be ignored.

\section{$21 \quad 2.3$ Measurements}

The DMS500 can record the PNDs at a frequency of $10 \mathrm{~Hz}$. However, our

23 experiments recorded the average of 10 measurements with a sampling frequency

24 of $1 \mathrm{~Hz}$ at both street and rooftop levels to improve the signal/noise ratio. The

25 measurements at street level were taken between 8 and 21 June 2006 (from 09:00

26 to $19: 00 \mathrm{~h}$ ) for 7 weekdays at three different heights (i.e., $0.20 \mathrm{~m}, 1.0 \mathrm{~m}$, and 2.60

$27 \mathrm{~m}$ above road level; hereafter called $\mathrm{A}, \mathrm{B}$ and $\mathrm{C}$, respectively). Further 28 measurements were taken on another weekday (22 June 2006) at rooftop level

29 (i.e., about $20 \mathrm{~m}$ above road level; hereafter called R). It should be noted that only

30 the street level measurements for 16 June have been compared with the rooftop

31 measurements, since the meteorology (wind speed, wind direction, temperature

32 and relative humidity) and the traffic volumes were similar on both days (see 
1 Table 1). Other results from this study are reported elsewhere (Kumar et al. 2 2008a).

To acquire a representative data set at each street level (i.e., at points A, B

4 and $\mathrm{C}$ ), the samples were taken for $20 \mathrm{~min}$ in an hour at each sampling point, on

5 two different occasions (i.e., 2 samples per hour, 10 min per sample) by manually

6 re-positioning the height of the probe every $10 \mathrm{~min}$. Rooftop measurements were

7 taken continuously between 09:00 and 19:00 h on 22 June 2006. Simultaneous

8 measurements at both levels (i.e., each sampling height) could not be performed,

9 due to the availability of only one instrument. With regards to street-level

10 sampling, since this was done in 60 separate time periods in the day, whilst the

11 PNC changed in an essentially random manner with respect to time, sufficient

12 measurements were made to draw tentative conclusions about the average PNCs

13 at street level.

14 Meteorological data (rooftop wind speed, hereafter called wind speed $U_{r}$,

15 wind direction, temperature, and relative humidity) were obtained from a weather

16 station, operated by the University's AT\&T laboratories on the roof of the

17 Department of Engineering building. The facility was about $40 \mathrm{~m}$ above the road

18 level at a point some $100 \mathrm{~m}$ from the sampling site. This location is above the 19 average height for Cambridge buildings and is not overlooked.

20 Traffic volumes were counted manually throughout each period of particle 21 measurements. The average traffic volumes during 16 June and 22 June were $221623 \pm 165$ vehicle $\mathrm{h}^{-1}$ and $1629 \pm 125$ vehicle $\mathrm{h}^{-1}$, respectively, of which cars and 23 vans (gasoline), cars and vans (diesel), buses, light duty vehicles (LDV), heavy 24 duty vehicles (HDV) and motorcycles were about 74.85\%, 19.15\%, 1\%, 3\%, $1 \%$ 25 and $1 \%$, respectively. The traffic speed through the test site was manually 26 measured be about $30 \mathrm{~km} \mathrm{~h}^{-1}$. Kumar et al. (2008a) give further details of the site, 27 the instrumentation, data acquisition and other street level results of this study.

\section{3. RESULTS AND DISCUSSION}

29 3.1 Particle number distributions at street level and rooftop 30 level

31 The PNDs, hourly averaged over the entire measurement period, at street 32 and rooftop levels are shown in Fig. 2a. The shape of street level PNDs at all three 
1 heights were found to be similar. The maxima of the PND profiles at three heights

2 were close to each other, showing a small, but consistent decrease with height.

3 However, significant differences can be seen between the PNDs at street and

4 rooftop levels. These observations depend on the traffic volume, ambient

5 meteorology (notably rooftop wind speed and wind direction), strength and sense

6 of rotation of any street canyon vortex. The PNDs at both street and rooftop levels

7 showed a typical bi-modal distribution, as seen in Fig. 2a. At street level the

8 PNDs showed peaks at about $30 \mathrm{~nm}$ and $100 \mathrm{~nm}$, whereas the rooftop PNDs

9 showed peaks at about $20 \mathrm{~nm}$ and $100 \mathrm{~nm}$. The peaks at smaller diameters (i.e., 20

$10 \mathrm{~nm}$ and $30 \mathrm{~nm}$ ) can be attributed to particles formed by nucleation and

11 condensation during the rapid cooling and dilution of semi-volatile species from

12 the exhaust gases with ambient air. This contrasts with the peak at about $100 \mathrm{~nm}$,

13 corresponding to larger particles formed in a vehicle's combustion chamber by

14 condensation of organic matter (Kittelson et al. 2004). Apart from exhaust

15 emissions, there may be a contribution of nucleating species (typically sulphates

16 and nitrates) from the upwind countryside at all levels. However, measurements at

17 minimum traffic levels and different wind speeds indicated that such particles

18 from the regional background made a minimal contribution.

19 If we treat the rooftop PNDs as background and subtract them from street

20 level PNDs, the resulting PNDs, shown in Fig. 2b, should reflect local traffic.

21 These resulting PNDs show an additional peak at about $10 \mathrm{~nm}$, which probably

22 reflected fresh emissions from traffic and/or tiny particles formed in the

23 atmosphere from various hydrocarbons precursors, because the background PNCs

24 has been shown to be relatively small and $\approx 15 \%$ of the total PNC (Kumar et al.

25 2008a). Interestingly, the street level PNDs are not similar to those obtained in

26 another recent study in a different Cambridge (UK) street canyon (Kumar et al.

27 2008b), where a significantly larger peak was observed at $\approx 13 \mathrm{~nm}$ and a smaller

28 peak at $\approx 87 \mathrm{~nm}$, in contrast to the large peak in Fig. $2 \mathrm{~b}$ at $\approx 30 \mathrm{~nm}$ and a smaller

29 peak at $\approx 100 \mathrm{~nm}$. This change in PNDs can be attributed to a type and volume of

30 traffic, driving conditions (more congested in this study) and the effect of the

31 surrounding built-up environment on the dispersion of exhaust emissions in the

32 street canyons. Apart from the difference in canyon geometry, the proportions of

33 gasoline and diesel engined vehicles were different in this study, being about $76 \%$

34 and $24 \%$, respectively, compared with $68 \%$ and $32 \%$, respectively, in the 
1 previous study on several (8-10\% of total traffic volume) bus routes (Kumar et al.

2 2008b). The present study comprised diesel cars and vans (19\%), buses (1\%),

3 light duty commercial vehicles (3\%) and heavy duty commercial vehicles (1\%)

4 (Kumar et al. 2008a). The relatively high proportion of buses in the previous

5 study would have had a disproportionate effect on the modal particle diameter,

6 because of the large number of particles emitted by these vehicles.

$7 \quad$ Since the three sampling points (A, B and C) recorded similar PNCs and

8 PNDs (differences in PNC ranged between 13\% and 21\%) for the entire period of

9 measurements, for simplicity the PNDs at A, B and C were averaged and used as

10 "street level" PNDs in the analysis below.

\section{$11 \quad 3.2$ Effect of wind speed on PNDs at street and rooftop 12 levels}

13 The half-hourly averaged wind speed and wind direction are used below to show

14 their effect on PNDs at street and rooftop levels. The wind speeds were 15 categorized in various ranges and the average PND for all measurements in each 16 category of wind speed is plotted in Fig. 3. The winds were always above $2.5 \mathrm{~m} \mathrm{~s}^{-}$

$17{ }^{1}$ during the study. The frequencies of winds in the designated categories of wind

18 speed $>2.5 \leq 3.5,>3.5 \leq 4.5,>4.5 \leq 5.5,>5.5<6.5,>6.5 \leq 7.5,>7.5 \leq 8.5$ and $>8.5 \leq 9.5$

$19 \mathrm{~m} \mathrm{~s}^{-1}$ were, respectively, 18, 18, 12, 35, 0, 0 and $17 \%$ during measurements at

20 street level, but 22, 20,13,12, 27, 6 and $0 \%$, respectively, during measurements

21 at rooftop level. Street level PNDs are plotted in Fig. 3a and seen to be acutely

22 dependent on the wind speed; the largest PNDs were found at the time of the

23 smallest wind speed and vice-versa. However, this effect was not consistent

24 across the entire range of particle sizes; for example, the variations in PNDs for 25 particles between 5 and $30 \mathrm{~nm}$ were significantly smaller than for particles 26 between 30 and $300 \mathrm{~nm}$. This shows a greater influence of wind speed on the 27 larger particles with diameters of 30-300 nm, than on smaller particles (5-30 nm).

28 This contrasts with rooftop PNDs, which are presented in Fig. 3b. They were 29 much more affected by changes in wind speed for smaller particles of 5 to $30 \mathrm{~nm}$ 30 than those between $30 \mathrm{~nm}$ and $300 \mathrm{~nm}$, whose abundances were independent of 31 wind speed. The larger variations in the PNDs between $30 \mathrm{~nm}$ and $300 \mathrm{~nm}$ at 32 street level seems mainly due to transport of particles out of the canyon (exchange 33 between the street canyon and the wind above, or ventilation), presumably due to 
1 dilution by turbulent mixing produced by the wind. Moreover, the influence of

2 rooftop PNDs on street level PNDs seems to be insignificant, since changes in 3 rooftop PNDs in the 30-300 $\mathrm{nm}$ size range are nearly negligible, despite the 4 change in wind speed (Fig. 3b), throughout the measurements. Therefore their 5 transport into the canyon should not affect the street level PNDs. During the entire

6 measurement period, conditions were found to be favourable for transporting

7 particles out of the street canyon through a street canyon vortex (see Fig. 1), since

8 the wind direction was nearly across the canyon (i.e., $\mathrm{SW}$ or about $22.5^{\circ}-67.5^{\circ}$ to

9 the street) and the wind speeds were always in excess of $1.5 \mathrm{~m} \mathrm{~s}^{-1}$ throughout the 10 measurements. The work of De Paul and Sheih (1986) showed that for wind 11 speeds above $1.5 \mathrm{~m} \mathrm{~s}^{-1}$ at an angle of more than $30^{0}$ to the street's axis (Oke 12 1988), a vortex is likely to form, as shown in Fig. 1. Furthermore, dilution of 13 particles at street level by clean air from above the canyon was most likely to be 14 dominated by mixing due to wind-produced turbulence, which dominates any 15 turbulence produced by traffic, when the wind blows across a regular street 16 canyon with a speed greater than $1.2 \mathrm{~m} \mathrm{~s}^{-1}$ (Kastner-Klein et al. 2003; Solazzo et 17 al. 2007).

$18 \quad 3.3$ Particle number concentrations in various size ranges 19 at street and rooftop levels

The PNDs can be described as consisting of distinct populations in 21 different size-modes and further quantified by their total particle number 22 concentrations (PNCs) in these size ranges. Consequently PNCs were obtained in 23 various size ranges by integrating the areas under PND curves over a given size 24 range; these size ranges were 5-10 nm, 10-30 nm, 30-300 nm and 300-1000 nm 25 and the number of particles within each range is referred to as $\mathrm{N}_{5-10}, \mathrm{~N}_{10-30}, \mathrm{~N}_{30-}$ 26300 and $\mathrm{N}_{300-1000}$, respectively. Particles within the first two size ranges (i.e., $\mathrm{N}_{5-30}$ ) 27 can be referred to as the nucleation mode, whereas those in $\mathrm{N}_{30-300}$ were referred 28 to as the accumulation mode.

29 The proportion of PNCs in each size range at both street and rooftop levels 30 are shown in, respectively, in Fig. 4 (a) and (b). At both levels, particles in the $\mathrm{N}_{5}$ 31300 size range accounted for most $(\approx 99.9 \%)$ of the PNCs, showing negligible 32 quantities of particles in the larger $\left(\mathrm{N}_{300-1000}\right)$ size range. These results in Fig. 4 33 are in accordance with Tuch et al. (1997), who reported that the contribution of 
1 particles larger than $500 \mathrm{~nm}$ to the overall PNC was negligible in the European

2 urban environment. Since the PNC in the $\mathrm{N}_{300-1000}$ size range at both street and

3 roof levels has been shown here to be almost negligible, this size range is not

4 considered separately in the subsequent analysis. Interestingly, particles in the

$5 \quad \mathrm{~N}_{30-300}$ size range dominated $\left(\approx 68 \%\right.$ of $\left.\mathrm{N}_{5-1000}\right)$ the PNCs at street level, whereas

6 particles in the $\mathrm{N}_{5-30}$ size range dominated $\left(\approx 66 \%\right.$ of $\left.\mathrm{N}_{5-1000}\right)$ the PNCs observed

7 at rooftop level. Our results for street level measurements also agree with those

8 measured by Longley et al. (2003) in a street canyon in Manchester, UK, where

9 particles in the $\mathrm{N}_{30-300}$ size range dominated the range 4.6 to $10000 \mathrm{~nm}$.

10 Figure 5 shows clear differences in the PNCs in each size range between

11 street and rooftop levels. A ratio, averaged over the entire sampling period, of

12 about 6.5 was observed between PNCs at street and rooftop levels in the $\mathrm{N}_{5-1000}$

13 range. This ratio changed significantly when the comparison was made for various

14 size ranges; it was respectively, $2.4,3.2,12.8$ and 6.6 for particles in the $\mathrm{N}_{5-10}$,

$15 \mathrm{~N}_{10-30}, \mathrm{~N}_{30-300}$ and $\mathrm{N}_{300-1000}$ size ranges. The highest ratio $(\approx 13)$ was observed for

16 the accumulation mode $\left(\mathrm{N}_{30-300}\right)$ particles. This was expected because of the larger

17 emissions (including particles formed during the cooling of exhaust gases) of

18 primary particles by the traffic at street level, and also the greater dilution by

19 stronger winds at rooftop level. Furthermore, this ratio $\mathrm{N}_{30-300}$ at street and rooftop

20 levels is plotted in Fig. 6, where it is seen to decrease with increasing wind speed.

21 This supports the statement above that the particles in this size range are largely

22 influenced by the wind speed. Interestingly, variations in this ratio were largely

23 dominated by the changes in street level PNCs $\left(\mathrm{N}_{30-300}\right)$ due to ventilation (Fig.

24 3a), since the PNCs in the $\mathrm{N}_{30-300}$ size range at rooftop level were nearly

25 unchanged, despite the change in wind speed, throughout the measurements (Fig. $263 b)$

27 Our previous analysis (Kumar et al 2007; Kumar at al. 2008a-c) showed 28 that the particles in the accumulation mode were nearly unaffected by the 29 transformations undergone by particles, so that their concentration only changes 30 when the air which they are suspended in is diluted by fresh, uncontaminated, air. 31 Assuming that particle numbers in the accumulation mode are, in fact, conserved, 32 the ratio $\left(\mathrm{N}_{5-30}: \mathrm{N}_{30-300}\right)$ at any level should indicate the rate of production of new 33 (nucleation mode) particles; this ratio, averaged over the entire sampling period, 34 was 0.52 at street level, compared with 2.49 at rooftop level. Interestingly, this 
1 ratio $\left(\mathrm{N}_{5-30}: \mathrm{N}_{30-300}\right)$ was reasonably constant at street level $(0.52 \pm 0.21)$

2 throughout the measurements, despite changes in wind speed (Fig. 6). However,

3 this ratio showed much higher values and variations $(2.49 \pm 1.01)$ at rooftop level

4 (Fig. 6), indicating the possibility of a much higher production of nucleation mode

5 particles at this level than at street level.

6 Vakeva et al. (1999) reported two important factors which can favour a

7 much greater production of particles at rooftop level than at street level: firstly,

8 the higher concentration of condensable gases and secondly, the smaller

9 concentrations of pre-existing particles. These arguments were later supported by

10 Kulmala et al. (2000), who concluded that small pre-existing aerosol

11 concentrations favour both the production of new particles and their growth to

12 measurable sizes in the atmosphere. Subsequently, Kerminen et al. (2001) found

13 that high concentrations of pre-existing particles both promote the condensation

14 of the semi-volatile vapours and disfavour both the growth of fresh nuclei and

15 their survival from high coagulational scavenging.

16 Our results seem to be in accordance with the above two conditions

17 favouring much higher particle production at rooftop level than at street level.

18 Firstly, smaller concentrations of pre-existing particles at rooftop level can be

19 seen from the ratio $\left(\mathrm{N}_{30-300}\right.$ at street level: $\mathrm{N}_{30-300}$ at rooftop level) of about 12.8.

20 Secondly, the possibly higher concentration of condensable gases at rooftop level

21 could be attributed in urban areas to atmospheric chemistry (including

22 photochemistry) producing sufficient amounts of condensable gases for gas-to-

23 particle conversion. The evidence for the above arguments is shown in Fig. 6 by

24 the ratio $\left(\mathrm{N}_{5-30}: \mathrm{N}_{30-300}\right)$, which indicates that the relative rate of production of new

25 particles at rooftop level increases with the wind speed. Also, the ratio $\left(\mathrm{N}_{30-300}\right.$ at

26 street level: $\mathrm{N}_{30-300}$ at rooftop level), which indicates the relative number of pre-

27 existing particles at each level, decreases with increased wind speed. Furthermore,

28 increasing the wind speed generates a shift of the particle number distributions, as

29 measured at the rooftop level, to finer diameters; this is shown in Fig. 7, which

30 plots the peak diameter in a number distribution against the wind speed. Also, the

31 increase of relative particle number concentrations in Fig. 6 indicates decreased

32 agglomeration and coalescence of particles at rooftop level. Similar evidence for

33 the formation of new particles and their growth in urban areas has been reported 
1 in many experimental (Makela et al. 1998; Vakeva et al. 1999; Charron and

2 Harrison 2003; Kulmala et al. 2004, Curtius 2006) studies.

Conversely, at street level the number and surface area of pre-existing

4 particles emitted from vehicles can be so large that condensation of gases on to

5 them outweighs any new particles being formed. This argument is supported by

6 the ratios $\left(\mathrm{N}_{5-30}: \mathrm{N}_{30-300}\right)$ in Fig. 6; they indicate the relative rate of production of

7 new particles. Also, the peak diameters in the particle number distributions are

8 seen in Fig. 7 to be nearly constant at street level, despite the change in wind

9 speed, throughout the measurements.

10 A nucleation event was also observed during the midday hours (between 11 11:00 $\mathrm{h}$ and 13:00 $\mathrm{h})$, when the weather was "bright sunny". The ratios $\left(\mathrm{N}_{5-30}: \mathrm{N}_{30}\right.$

12300 ) during this time increased from an overall average of 2.49 to 3.59. This

13 increase might well be due to photochemically induced nucleation, in addition to

14 new particles being produced through gas-to-particle conversion. The relative

15 contributions of photochemically induced nucleation and nucleation through gas-

16 to-particle conversion could not be deduced because of the limited availability of

17 measurements. However, Wehner and Weidensohler (2003) and Vakeva et al.

18 (1999) have reported strong evidence for an association between the formation of

19 new particles and nucleation, photochemically induced by solar radiation.

\section{$20 \quad 3.4$ Correlation of PNCs with traffic volume and wind speed}

Traffic volume and rooftop wind speed are generally the principal

22 variables influencing PNCs at both street and rooftop levels of a canyon. In order

23 to show the effect of rooftop wind speed on PNC, the PNCs in the $\mathrm{N}_{5-30}$ and $\mathrm{N}_{30}$

24300 size ranges at both levels were correlated with wind speed using:

$$
N_{\mathrm{i}-\mathrm{j}}=a U_{r}^{-n}
$$

26 where $N_{\mathrm{i}-\mathrm{j}}$ is the PNC in any given size range, $a$ is constant and $n$ is the exponent 27 of wind speed, $U_{r}$. Table 2 shows the results. It is clear that the values of $n$ are 28 constant and positive at street level, but negative at rooftop level. This indicates

29 that PNCs decrease with increased wind speed at street level, but the opposite 30 trend holds at rooftop level. The values of $n$ for each size range at street level were 31 close to unity, as shown in Fig. 8a. This confirms the idealised inverse $(n \approx 1)$

32 wind speed law (Ketzel et al. 2002). However, the values of $\mathrm{R}^{2}$ were larger for $33 \mathrm{~N}_{30-300}$ than for $\mathrm{N}_{5-30}: 0.48$ compared to 0.28 . By contrast, rooftop level PNCs in 
1 the $\mathrm{N}_{5-30}$ size range correlated better with wind speed than those for PNCs in the

$2 \mathrm{~N}_{30-300}$ size range: $\mathrm{R}^{2}$ was 0.80 compared with 0.58 . Moreover, the negative values

3 of $n$ for both size ranges at rooftop level reflect that PNCs increase with wind

4 speed, as seen in Fig. 8c. Also, there were much higher variations in the values of

$5 \quad n$ at rooftop level than at street level. One of the highest values of $\mathrm{R}^{2}$ and the value

6 of $n$ with largest magnitude is $n=-2.3$, indicating a greater concentration of

7 particles with higher wind speed for $\mathrm{N}_{5-30}$. This again suggests more formation of

8 particles at rooftop level. Harrison et al. (2000) and Charron and Harrison (2003)

9 also reported that "cleaner atmospheres" created by stronger winds favour the

10 occurrence of large numbers of smaller particles. The dependence of the PNCs at

11 both levels on wind speed is clearly of prime importance, with traffic volume as

12 the next most important factor.

13 The correlations between the PNCs in each size range at both levels and

14 the volume of traffic at both levels are shown in Table 3, for which it was

15 assumed that $N_{\mathrm{i}-\mathrm{j}}$ is linear in the traffic volume. As expected, these correlations

16 were found to be better at street level than at rooftop level. Also worthy of note, is

17 that the values of $\mathrm{R}^{2}$ at street level are for correlations showing linearly increasing

18 PNCs in each size range with increasing traffic volume, as shown in Fig 8b. On

19 the other hand, at rooftop level, the correlations surprisingly show linearly

20 decreasing PNCs in each size range with increasing traffic volume, as illustrated

21 in Fig. 8d.

22 Finally, it is important to investigate the combined effect of both wind 23 speed and traffic volume on the PNCs for each size range. In order to remove the 24 prime dependence of the PNCs on traffic volume, each PNC was divided by the 25 traffic volume and this was used as a primary variable and plotted against wind 26 speed. Such a correlation can be represented by changing Eq. (1) to:

$$
N_{i-j} / T^{m}=a U_{r}^{-n}
$$

28 where $m$ is the exponent (assumed to be unity) of traffic volume $(T)$. The results 29 of correlating the normalised PNCs in each size range with Eq. (2) at street level 30 are given in Table 4. The best fit values of $n$ are similar to those presented in 31 Table 2 (PNCs vs $U_{r}$ ) and Table 3 (PNCs vs $T$ ); this confirms the individual 32 relations of the PNCs with wind speed (Table 2) and traffic volume (Table 3), 33 showing an equal influence of wind speed and traffic volume on the PNCs. 34 Furthermore, correlations for the normalised PNCs in each size range with Eq. (2) 
1 at rooftop level (Table 4) were fairly similar to those presented in Table 2 (PNCs

2 vs $U_{r}$ ), but much better than those shown in Table 3 (PNCs vs $T$ ), showing a much

3 larger influence on the PNCs of wind speed than traffic volume.

\section{4. SUMMARY AND CONCLUSIONS}

Particle number distributions were measured at both street and rooftop 6 levels in a Cambridge (UK) street canyon. Measurements were taken at three 7 different heights (i.e., $0.20 \mathrm{~m}, 1.0 \mathrm{~m}$ and $2.60 \mathrm{~m}$ ) close to the road, whereas at 8 rooftop level measurements were taken $\approx 20 \mathrm{~m}$ above the road. The PNDs showed

9 a typical bi-modal distribution at both levels, peaking at about $30 \mathrm{~nm}$ and $100 \mathrm{~nm}$ 10 at street level, and about $20 \mathrm{~nm}$ and $100 \mathrm{~nm}$ at rooftop level. Closer inspection of 11 the measurements indicated that street level PNDs depended more on wind speed 12 for particles in $\mathrm{N}_{30-300}$ size range than particles in $\mathrm{N}_{5-30}$ size range. Conversely, 13 rooftop PNDs depended more on wind speed for the particles in $\mathrm{N}_{5-30}$ size range 14 than did particles in $\mathrm{N}_{30-300}$ size range, whose PND was hardly altered by a 15 change in wind speed.

At both levels, the PNCs in $\mathrm{N}_{5-300}$ accounted for more than $99 \%$ of the total $\left(\mathrm{N}_{5-1000}\right)$ PNCs. Street level PNCs were dominated by the particles in the $\mathrm{N}_{30-}$ 300 size range, whereas rooftop level PNCs were dominated by particles in the $\mathrm{N}_{5-}$ 30 size range. One interesting result of this study was the ratios of PNCs at rooftop and street levels. A ratio of about 6.5 was observed between street and rooftop

21 level PNCs in the $\mathrm{N}_{5-1000}$ size range. However, this ratio changed significantly for 22 other size ranges, showing the highest ratio for particles in $\mathrm{N}_{30-300}$ size range. This 23 was attributed to the larger emissions of primary particles from traffic at the street 24 level and also more intense dilution by stronger winds at rooftop level. The 25 assumption was checked that particles in the $\mathrm{N}_{30-300}$ size range (accumulation 26 mode) were largely unaffected by the transformation processes, i.e., changes in 27 concentration were only due to dilution of traffic-produced particles by "clean" 28 air from above so that their number could be assumed to be conserved. In this case 29 the ratios $\left(\mathrm{N}_{5-30}: \mathrm{N}_{30-300}\right)$ at any level should indicate the rate of production of new 30 particles. This ratio was about 5 times larger at rooftop level than at street level, 31 indicating a much larger relative production of nucleation mode particles at 32 rooftop level than at street level. This is in conjunction with less efficient 33 scavenging mechanisms at rooftop level, due to the presence of fewer 
1 accumulation mode particles (Kerminen et al. 2001). The production of nucleation

2 mode particles (and also a nucleation event) at rooftop level were attributed to

3 both the production of new particles through gas-to-particle conversion and

4 photochemically induced nucleation, since conditions were found to be favourable

5 for both processes. However the relative contributions of both these two

6 nucleation processes could not be identified due to a lack of measurements.

7 The PNCs in each size range at street level were found to be inversely

8 correlated with the wind speed and linearly correlated with the traffic volume.

9 Also, the PNCs in the $\mathrm{N}_{30-300}$ size range at street level were found to be largely

10 influenced by both the wind speed and the traffic volume. The correlation was

11 weaker for PNCs in the $\mathrm{N}_{5-30}$ size range. These results support our earlier findings

12 (Kumar et al. 2007; Kumar et al. 2008a-c). On the other hand, the PNCs in each

13 size range at rooftop level showed a positive correlation with wind speed and a

14 surprising negative correlation with the traffic volume. Moreover, the PNCs in the

$15 \mathrm{~N}_{5-30}$ size range at rooftop level showed a much larger influence of wind speed

16 than did the PNCs in the $\mathrm{N}_{30-300}$ range.

17 Since these results are based on short-time measurements, a study with

18 simultaneous measurements at both levels, over a much longer duration would be 19 useful.

\section{ACKNOWLEDGEMENTS}

Prashant Kumar thanks Cambridge Commonwealth Trust and Overseas

22 Research Scholarship award for providing the financial support for his Ph.D. The

23 authors also thank Dr. J.S. Dennis for lending the DMS500 for the study.

\section{6. REFERENCES}

AQEG (2005) Particulate matter in the United Kingdom, Defra London, 444 pp

Bauman SE, Ferek R, Williams ET, Finston HL, Ferrand EF, Santowski J (1982) Street level versus rooftop sampling: carbon monoxide and aerosol in New York city. Atmos Environ 16:2489-2496

28 Biskos G, Reavell K, Collings N (2005) Description and theoretical analysis of a Differential Mobility Spectrometer. Aerosol Sci and Technol 39:527-541

Charron A, Harrison RM (2003) Primary particle formation from vehicle emissions during exhaust dilution in the road side atmosphere. Atmos Environ 37:4109-4119

Collings N, Reavell K, Hands T, Tate J (2003) 194 Roadside aerosol measurements with a fast particle 
Curtius J (2006) Nucleation of atmospheric aerosol particles. C R Physique 7:1027-1045

2 Davidson C, Phalen R, Solomon P (2005) Airborne particulate matter and human health: a review. Aerosol

$3 \quad$ Sci Technol 39:737-749

4 De Paul FT, Sheih CM (1986) A tracer study of dispersion in an urban street canyon. Atmos Environ $20: 455-459$

Harrison RM, Grenfell JL, Savage N, Allen A, Clemitsaw KC, Penkett S, Hewitt CN, Davison B (2000) Observation of new particle production in the atmosphere of a moderately polluted site in eastern England. J Geophysical Res 105:17819-17832

Hinds WC (1999) Aerosol technology: Properties, behaviour and measurement of airborne particles (ed), $2^{\text {nd }}$ edn. John Wiley \& Sons, UK, 783 pp

Kastner-Klein P, Fedorovich E, Ketzel M, Berkowicz R, Britter R (2003) The modelling of turbulence from traffic in urban dispersion models - Part II: evaluation against laboratory and full-scale concentration measurements in street canyons. Environ Fluid Mech 3:145-172

Kerminen V-M, Pijrola L, Kulmala M (2001) How significantly does coagulational scavenging limit atmospheric particle production? J Geophysical Res 106:24119-24125

Ketzel M, Berkowicz R, Muller WJ, Lohmeyer A (2002) Dependence of street canyon concentrations on above-roof wind speed - implications for numerical modelling. Int J Environ Pollut 17:356-366

Kittelson DB, Watts WF, Johnson JP (2004) Nanoparticle emissions on Minnesota highways. Atmos Environ 38:9-19

Kulmala M, Pijrola L, Makela JM (2000) Stable sulphate clusters as a source of new atmospheric particles. Nature 404:66-69

Kulmala M, Vehkamaki H, Petaja T, Dal Maso M, Lauri A, Kerminen V-M, Birmili W, McMurry PH (2004) Formation and growth rates of ultrafine particles: a review of observations. J Aerosol Sci 35:143-176

Kumar P, Fennel P, Britter R (2007) Measurements and dispersion behaviour of particles in various size ranges $(5 \mathrm{~nm}>\mathrm{dp}<1000 \mathrm{~nm})$ in a Cambridge street canyon Proccedings of the 11th International Conference on Harmonisation within Atmospheric Dispersion Modelling for Regulatory Purposes Cambridge, UK, p 368-372 http://www.harmo.org/conferences/proceedings/_Cambridge/publishedSections/Pp368-372.pdf

Kumar P, Fennell P, Britter R (2008a) Measurements of particles in the 5-1000 nm range close to road level in an urban street canyon. Sci Total Environ 390:437-447

Kumar P, Fennell P, Langley D, Britter R (2008b) Pseudo-simultaneous measurements for vertical variations of coarse, fine and ultra fine particles in an urban street canyon. Atmos Environ DOI:10.1016/j.atmosenv.2008.01.010

Kumar P, Fennell P, Britter R (2008c) Effect of wind direction and speed on the dispersion of nucleation and accumulation mode particles in an urban street canyon. Sci Total Environ (article in press)

Li XL, Wang JS, Tu XD, Liu W, Huang L (2007) Vertical variations of particle number concentration and size distribution in a street canyon in Shanghai, China. Sci Total Environ 378:306-316

Longley ID, Gallagher MW, Dorsey JR, Flynn M, Allan JD, Alfarra D, Inglish D (2003) A case study of aerosol $\left(4.6 \mathrm{~nm}<\mathrm{D}_{\mathrm{p}}<10 \mu \mathrm{m}\right)$ number and mass size distribution measurements in a busy street canyon in Manchester, U.K. Atmos Environ 37:1563-1571

Makela J, Hameri K, Vakeva M, Aalto P, Laakso L, Kulmala M, Charlson RJ (1998) On the spatial scale of new particle formation in Sothern Finland. J Aerosol Sci 29:5215-5216 
Oberdorster G (2000) Toxicology of ultrafine particles: in vivo studies. Philos Trans R Soc London 2 A358:2719-2740

3 Oke TR (1988) Street design and urban canopy layer climate. Energy and Buildings 11:103-113

4 Peters A, Wichmann HE (2001) Epidemiological basis for particulate air pollution health standards. $5 \quad$ Epidemiology 12:544

6 Pope III CA (2000) Review: Epidemiological basis for particulate air pollution health standards. Aerosol Sci $7 \quad$ Technol 32:4-14

8 Qin Y, Kot SC (1993) Dispersion of vehicular emission in street canyons, Guanghou city, South China 9 (P.R.C.). Atmos Environ 27B:283-291

10 QUARG (1996) Airborne particulate matter in the United Kingdom Technical report, Department of 11 Environment, London, UK, Technical report, Department of Environment, London, 188 pp

12 Schauer JJ, Hildermann LM, Mazurek MA, Cass GR, T. SBR (1996) Source apportionment of airborne 13 particulate matter using organic compounds as tracers. Atmos Environ 30:3837-3855

14 Shi PJ, Khan AA, Harrison RM (1999) Measurements of ultra fine particle concentration and size distribution 15 in the urban atmosphere. Sci Total Environ 235:51-64

16 Solazzo E, Vardoulakis S, Cai X (2007) Evaluation of traffic-producing turbulence schemes within operating schemes within operational street pollution models using road side measurements Atmos Environ 41:5357-5370

19 Symonds JPR, Reavell KSJ, Olfert JS, Campbell BW, Swift SJ (2007) Diesel soot mass calculations in realtime with a differential mobility spectrometer. J Aerosol Sci 38:52-68

Tuch T, Brand P, Wichmann HE, Heyder J (1997) Variations of particle number and mass concentration in various size ranges of ambient aerosols in eastern Germany. Atmos Environ 31:4193-4197

Vakeva M, Hameri K, Kulmala M, Lahdes R, Ruuskanen J, Laitinen T (1999) Street level versus rooftop concentrations of submicron aerosol particles and gaseous pollutants in an urban street canyon. Atmos Environ 33:1385-1397

Van Dingenen R, Raes F, Putaud J-P, Baltensperger U, Charron A, Facchini M-C, Decesari S, Fuzzi S, Gehrig R, Hansson H-C (2004) A European aerosol phenomenology - 1: physical characterstics of particulate matter at kerbside, urban, rural and background sites in Europe. Atmos Environ 38:25612577

Vardoulakis S, Fisher BRA, Pericleous K, Gonzalez-Flesca N (2003) Modelling air quality in street canyons: a review. Atmos Environ 37:155-182

Vardoulakis S, Gonzalez-Flesca N, Fisher BEA (2002) Assessment of traffic-related air pollution in two street canyons in Paris: implications for exposure studies. Atmos Environ 36:1025-1039

Wehner B, Weidensohler A (2003) Long term measurements of submicrometer urban aerosols: statistical analysis for correlations with meteorological conditions and trace gases. Atmos Chem Physics 3:867879

Zoumakis NM (1995) A note on average vertical profiles of vehicular pollutant concentrations in urban Street Canyons. Atmos Environ 29: 3719-3725 


\section{FIGURE CAPTIONS}

2 Fig. 1.

3 Schematic diagram of sampling site, showing the traffic flow, wind direction and

4 a likely vortex, as described in the text (figures not to scale).

5 Fig. 2.

6 (a) Hourly averaged PNDs at both street and rooftop levels, and (b) resulting

7 PNDs after subtracting of roof top level PNDs from street level PNDs, at various

8 heights.

9 Fig. 3.

10 Effect of wind speed on particle number distributions at (a) street level (averaged

11 over locations A, B and C), and (b) rooftop level. Both figures show averages of

12 half-hourly wind speeds and PND data for various ranges of wind speed.

13 Fig. 4.

14 Proportions of hourly averaged PNCs in various size ranges at (a) street, and (b) 15 rooftop level.

16 Fig. 5.

17 Comparison of hourly averaged PNCs in various size ranges at both street and

18 rooftop levels. The error bars show the standard deviation of hourly averaged

19 values of the PNCs.

20 Fig. 6.

21 Ratios of the PNCs in different size ranges (i.e., $\mathrm{N}_{5-30}$ and $\mathrm{N}_{30-300}$ ) at street and

22 rooftop levels plotted against the hourly averaged wind speed.

23 Fig. 7.

24 The peak diameters of hourly averaged particle number distributions plotted

25 against the wind speed at both street and rooftop levels.

26 Fig. 8.

27 Plots of particle number concentrations against (a) wind speed and (b) traffic

28 volume at street level, and against (c) wind speed and (d) traffic volume at rooftop 29 level. 


\section{TABLES}

\section{Table 1}

3 Comparison of meteorological parameters and traffic volume at both street and

4 rooftop levels during the entire measurements. The values shown in the table are

5 the hourly average (Av) over the entire measurements and the standard deviations

6 (SD) of hourly averaged values.

\begin{tabular}{|c|c|c|c|c|c|c|c|c|c|}
\hline \multirow[t]{2}{*}{ Date } & \multicolumn{2}{|c|}{$\begin{array}{l}\text { Wind speed } \\
\qquad\left(\mathrm{m} \mathrm{s}^{-1}\right)\end{array}$} & \multicolumn{2}{|c|}{$\begin{array}{c}\text { Relative } \\
\text { Humidity }(\%)\end{array}$} & \multicolumn{2}{|c|}{$\begin{array}{c}\text { Temperature } \\
\left({ }^{0} \mathrm{C}\right)\end{array}$} & \multicolumn{2}{|c|}{$\begin{array}{c}\text { Traffic } \\
\text { Volume } \\
\left(\text { veh }^{-1}\right)\end{array}$} & \multirow[t]{2}{*}{$\begin{array}{c}\text { Wind } \\
\text { Direction }\end{array}$} \\
\hline & Av & $\mathrm{SD}$ & Av & $\mathrm{SD}$ & $\mathrm{Av}$ & SD & Av & $\mathrm{SD}$ & \\
\hline 16 June & 6 & 1.8 & 39 & 2.6 & 25 & 0.6 & 1623 & 165 & Southwest \\
\hline 22 June & 6 & 1.6 & 44 & 5.9 & 20 & 0.9 & 1629 & 125 & Southwest \\
\hline
\end{tabular}




\section{Table 2}

2 Results of correlating PNCs in various size ranges with the wind speed at both 3 street and rooftop levels.

\begin{tabular}{lcccccc}
\hline & \multicolumn{2}{c}{$\mathrm{N}_{5-30}$} & \multicolumn{2}{c}{$\mathrm{N}_{30-300}$} & \multicolumn{2}{c}{$\mathrm{N}_{5-1000}$} \\
\cline { 2 - 7 } Level & \multicolumn{2}{c}{$\mathrm{R}^{2}$} & $n$ & $\mathrm{R}^{2}$ & $n$ & $\mathrm{R}^{2}$ \\
& 0.94 & 0.28 & 0.95 & 0.48 & 0.97 & 0.20 \\
Street & & & & & & \\
Rooftop & -2.3 & 0.80 & -0.5 & 0.58 & -1.59 & 0.81 \\
\hline
\end{tabular}




\section{$1 \quad$ Table 3}

2 Correlations of PNCs in various size ranges with traffic volume at both street and 3 rooftop levels.

\begin{tabular}{lccc}
\hline & \multicolumn{3}{c}{$\mathrm{R}^{2}$} \\
Level & \multicolumn{3}{c}{} \\
\cline { 2 - 4 } & $\mathrm{N}_{5-30}$ & $\mathrm{~N}_{30-30}$ & $\mathrm{~N}_{5-1000}$ \\
\hline Street & 0.27 & 0.49 & 0.57 \\
Rooftop & 0.28 & 0.20 & 0.28 \\
\hline
\end{tabular}




\section{$1 \quad$ Table 4}

2 Correlations between the normalised PNCs in various size ranges and the wind 3 speed at both street and rooftop levels.

\begin{tabular}{lcccccc}
\hline & \multicolumn{2}{c}{$\mathrm{N}_{5-30} / T$} & $\mathrm{~N}_{30-300} / T$ & $\mathrm{~N}_{5-1000} / T$ \\
\cline { 2 - 6 } Level & \multicolumn{1}{c}{$n$} & $\mathrm{R}^{2}$ & $n$ & $\mathrm{R}^{2}$ & $n$ & $\mathrm{R}^{2}$ \\
& & & & & & \\
\hline Street & 0.76 & 0.25 & 0.76 & 0.49 & 0.78 & 0.20 \\
& & & & & & \\
Rooftop & -2.4 & 0.78 & -0.75 & 0.55 & -1.84 & 0.77 \\
& & & & & & \\
\hline
\end{tabular}

4 


\section{Fig. 1.ppt}

Click here to download colour figure: Fig. 1_N-S orient.ppt

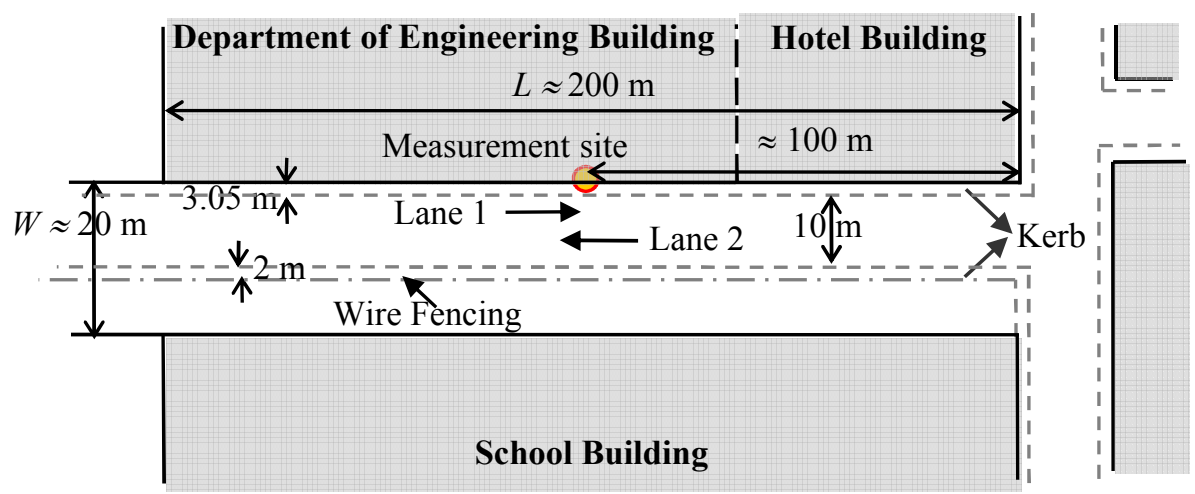

$\mathrm{W} \underset{\mathrm{S}}{\stackrel{\mathrm{f}}{\downarrow}} \mathrm{E}$

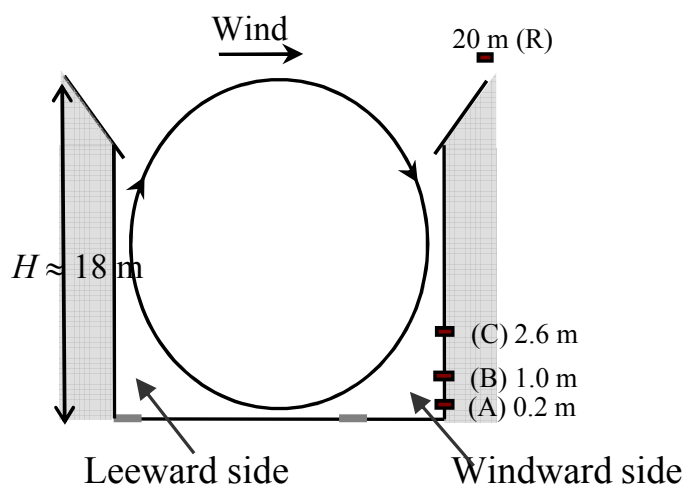


Fig. 2.ppt

Click here to download colour figure: Fig. 2.ppt

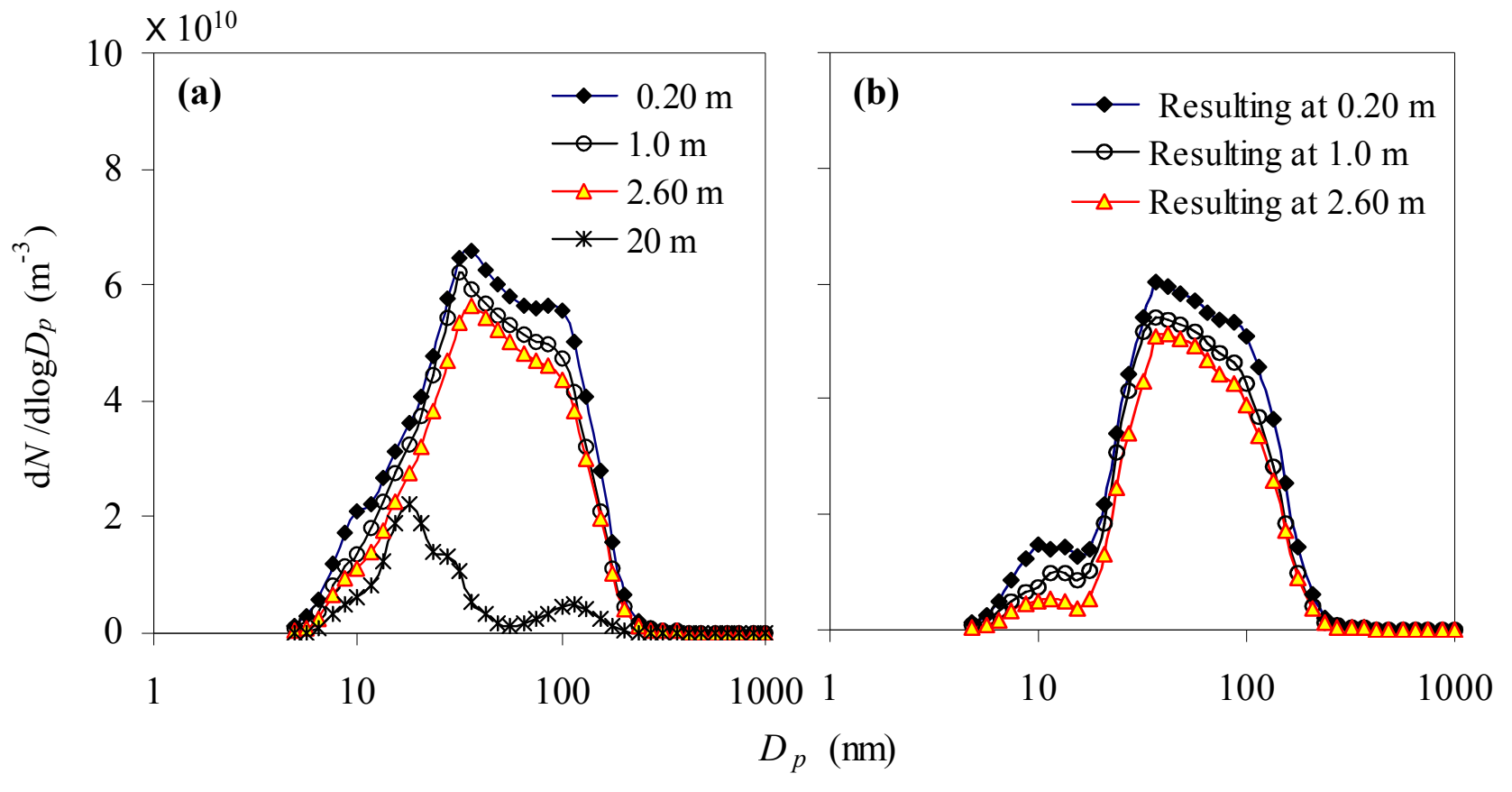




\section{Fig. 3.ppt}

Click here to download colour figure: Fig. 3.ppt

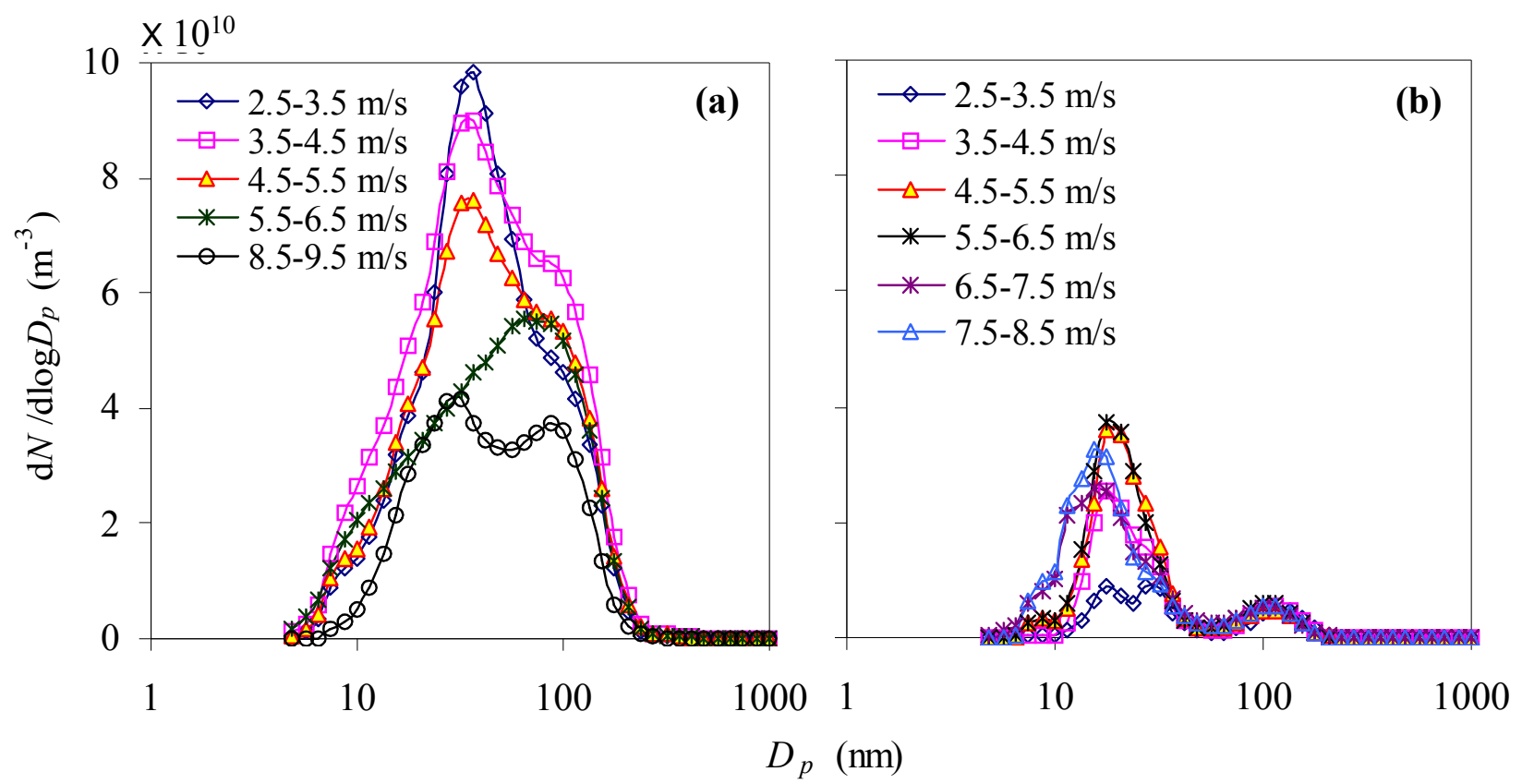


(a)

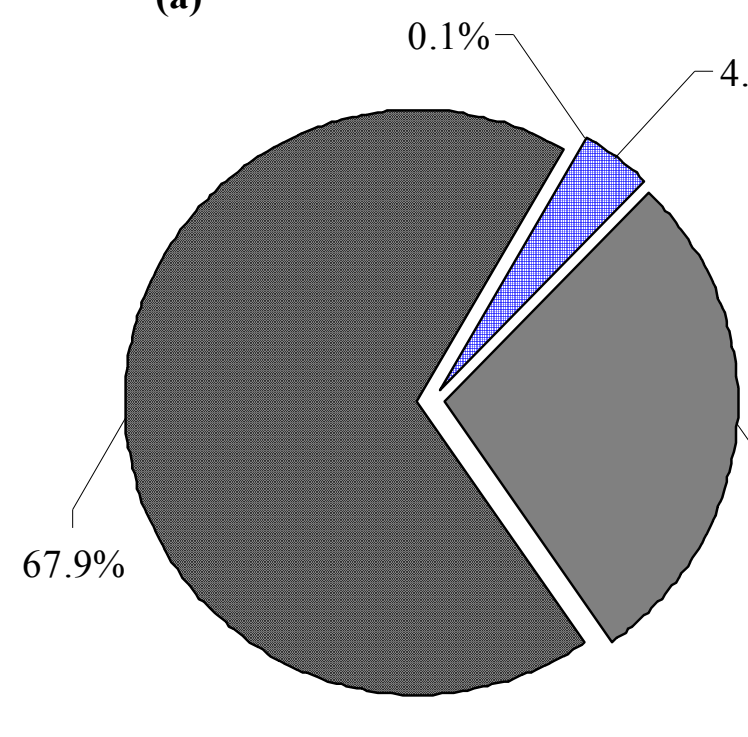

(b)

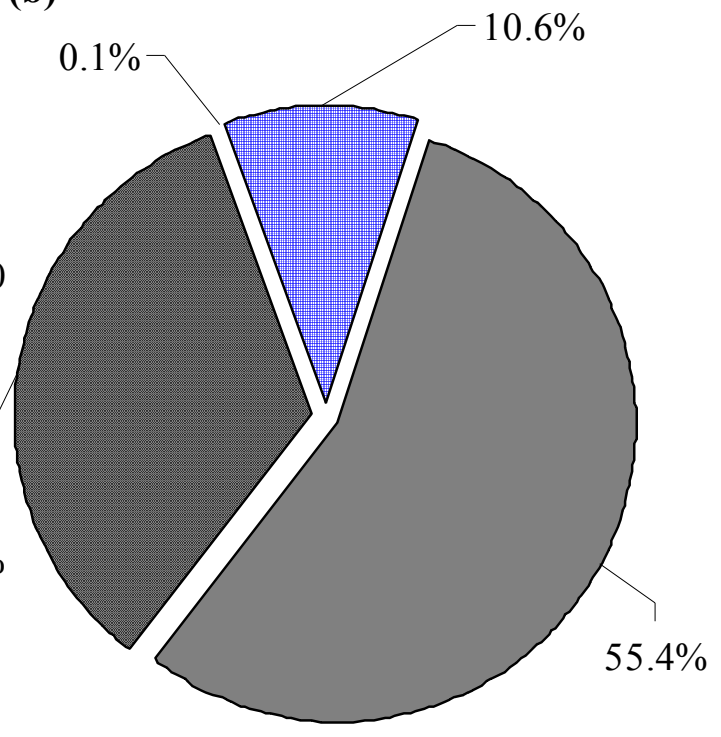


Click here to download colour figure: Fig. 5.ppt

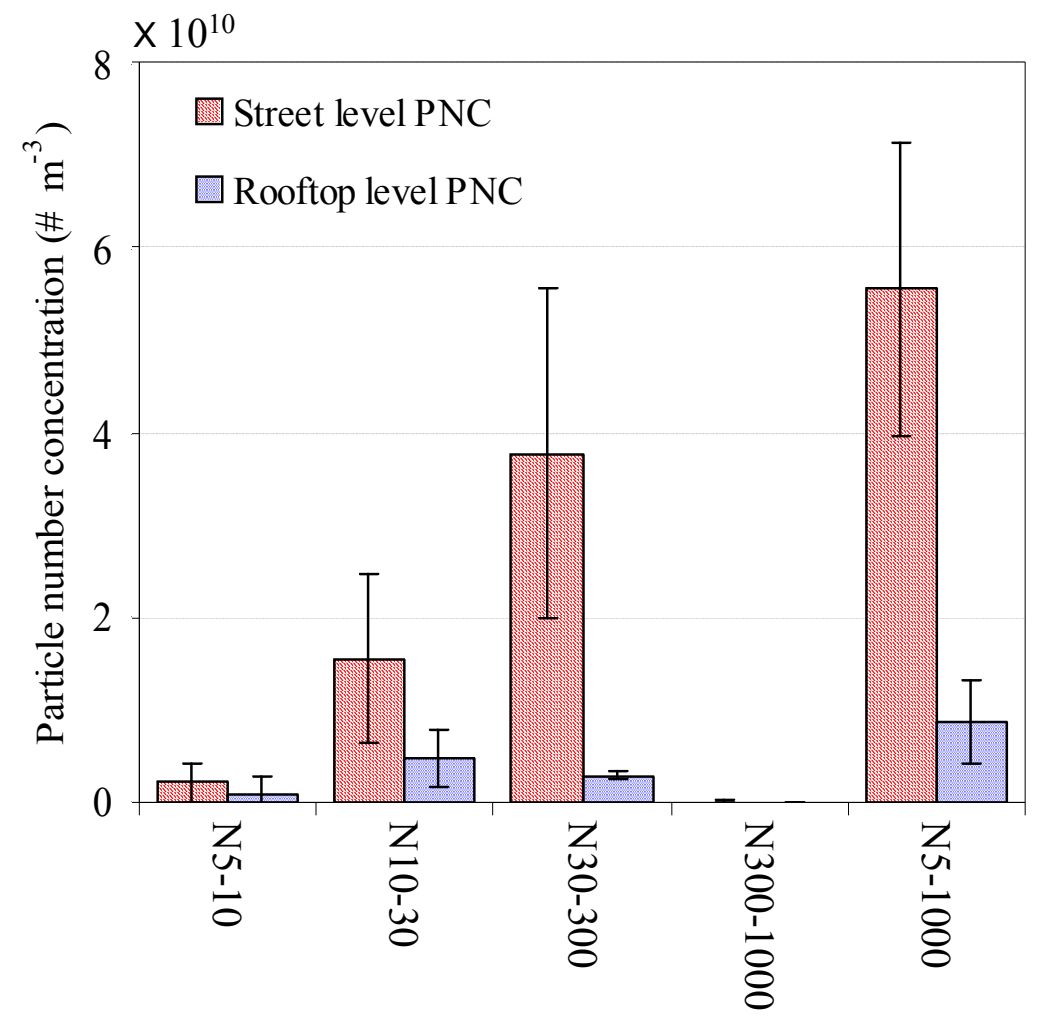


Fig. 6.ppt

Click here to download colour figure: Fig. 6.ppt

- Street level $\circ$ Rooftop level $\Delta$ N30-300 (street)/N30-300(rooftop)

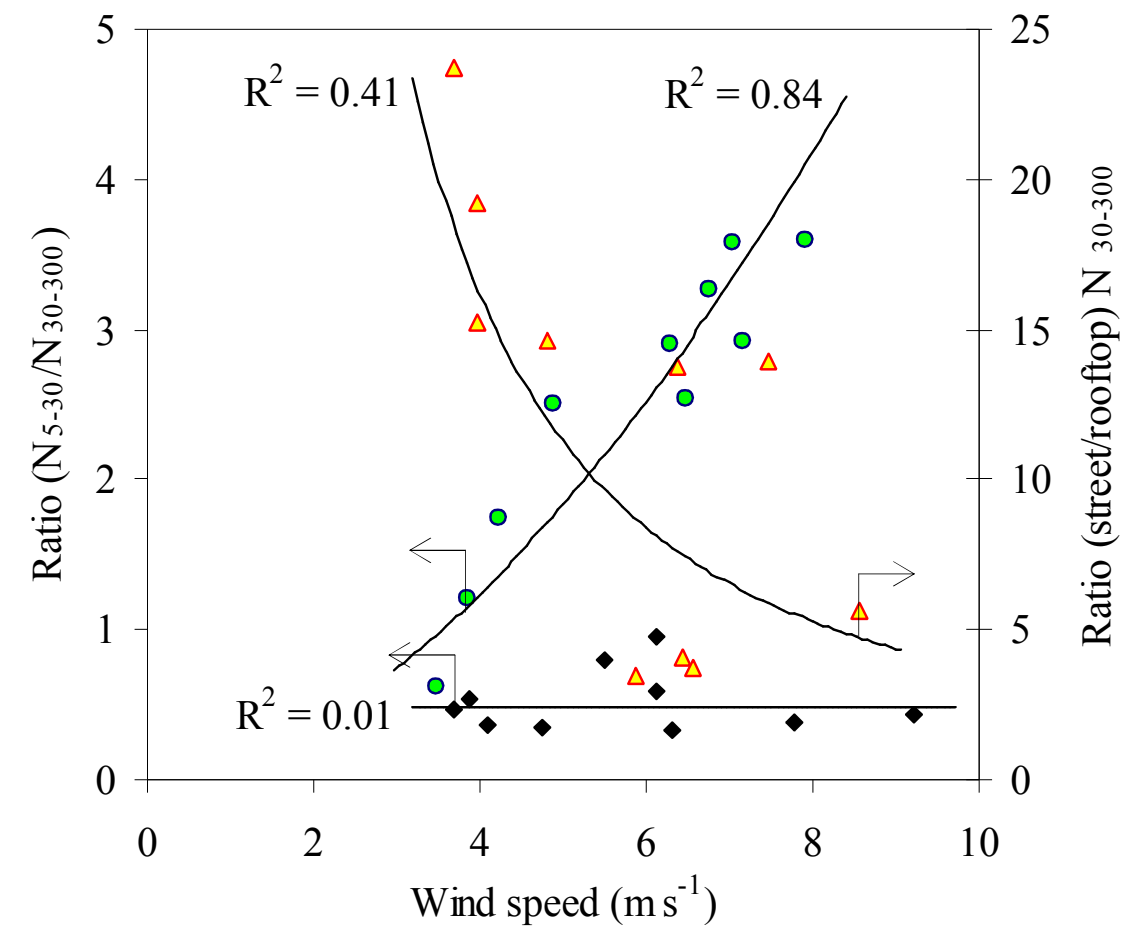




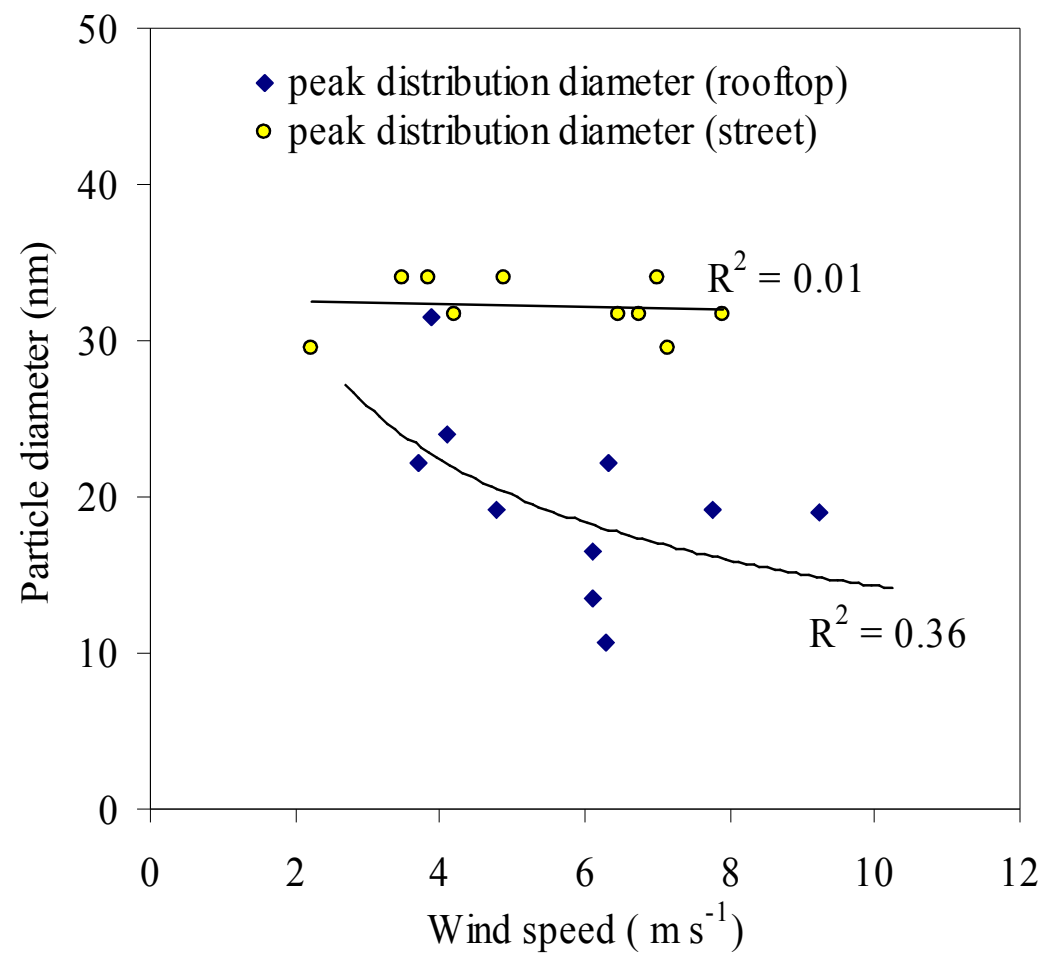



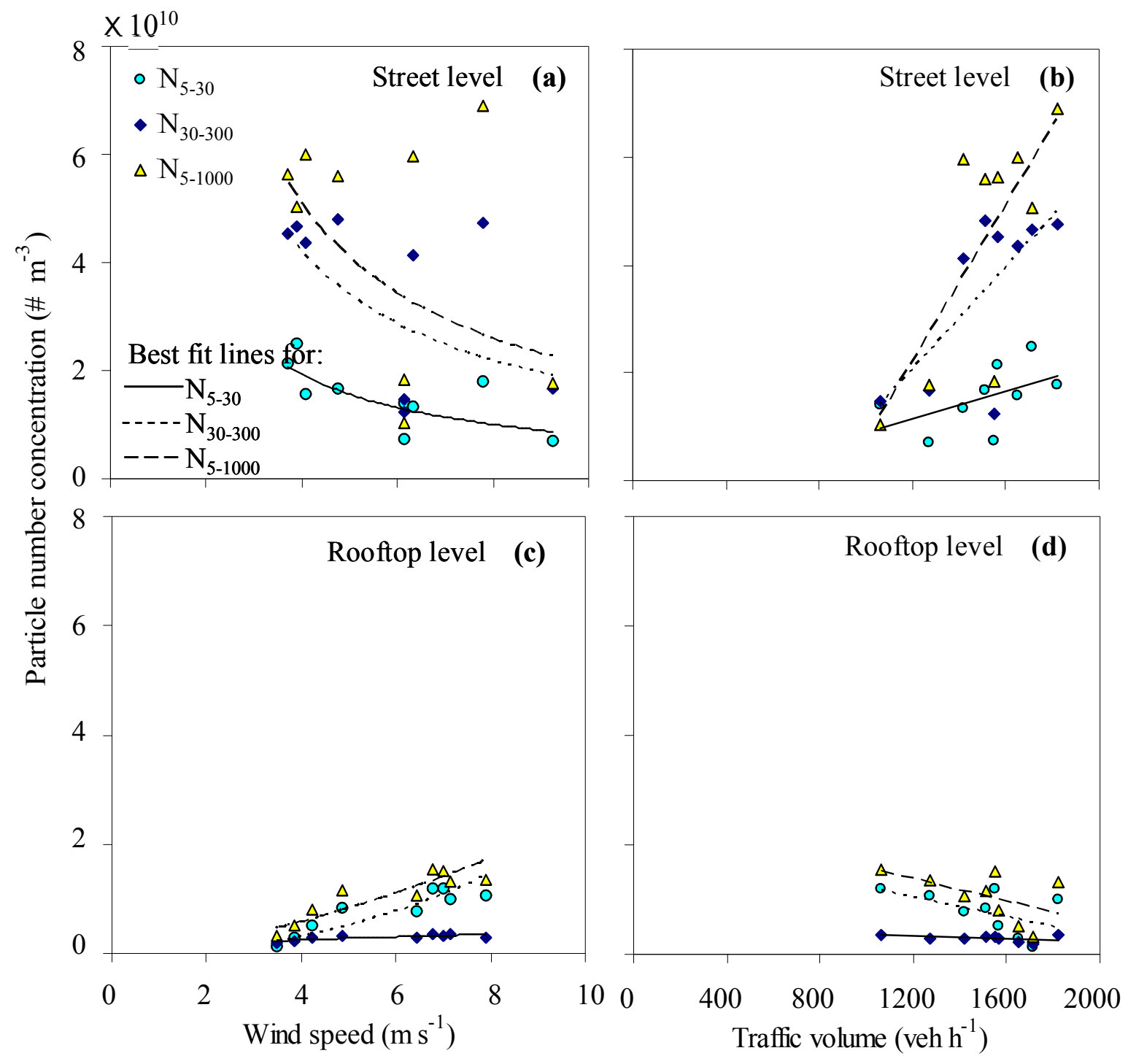